Creating Productive and Upcoming Sport Education Profesional Hmzanwadi University

Vol.4, No.2, Desember 2021, Hal. 158-164

e-ISSN 2614-8781

\title{
PROFIL TES PARAMETER ATLET CABANG OLAHRAGA TARUNG DERAJAT
}

\author{
Irwan Setiawan 1

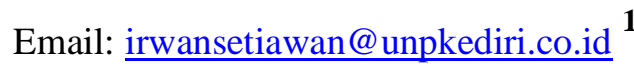 \\ ${ }^{1}$ Program Studi Pendidikan Jasmani, Kesehatan Dan Rekreasi, Fakultas Ilmu Kesehatan Dan Sains \\ Universitas Nusantara PGRI Kediri
}

\begin{abstract}
Abstrak
Capaian kemajuan prestasi Tarung Derajat yang ada saat ini perlu ditingkatkan supaya mencapai hasil yang maksimal. Banyak cara untuk meningkatan prestasi cabang olahraga khusus tarung derajat. Salah satunya adalah dengan cara mengevaluasi dan mengukur tingkat kondisi fisik masing-masing atlet. Komponen kondisi fisik yang dapat diukur untuk mengetahui kemampuan atlet. Sebagai mana kita ketahui bahwa tanpa pengukuran yang tepat dan akurat akan mustahil menentukan program latihan yang tepat. Oleh karenanya penting sekali bagi peneliti untuk melakukan penelitian guna melihat sejauh mana tingkat kondisi fisik atlet Puslatkab Kediri cabang olahraga Tarung Derajat melalui tes parameter sehingga membantu dan dapat menjadi tolak ukur penentuan program latihan bagi KODRAT kabupaten Kediri. Penelitian ini menggunakan tes dan pengukuran terhadap 7 komponen tes kondisi fisik yang digunakan untuk menunjang kemampuan fisik bagi atlet tarung derajat. Penelitian ini teknik analisis data yang digunakan untuk menguji data dalam penelitian ini adalah analisis deskriptif persentase. Dimana hasil dari data penelitian dihitung dalam jumlah persen berapa atlet yang dalam katagori baik sekali, baik, cukup, kurang dan kurang sekali. Setelah dilakukan analisis data penelitian maka dapat diambil beberapa kesimpulan bahwa kondisi fisik secara keseluruhan atlet tarung derajat pada Puslatkab Kediri $47 \%$ termasuk dalam cukup, dan 53\% termasuk dalam kategori kurang.
\end{abstract}

Kata Kunci: Tes parameter, Atlet Tarung Derajat

\begin{abstract}
The current progress of Tarung Derajat's achievements needs to be improved in order to achieve maximum results. There are many ways to improve sports performance. One of them is by evaluating and measuring the level of physical condition of each athlete. Components of physical condition that can be measured to determine the athlete's ability. As we know that without precise and accurate measurements it will be impossible to determine the right exercise program. Therefore, it is very important for researchers to conduct research to see how far the level of physical condition of athletes from the Puslatkab Kediri in the Tarung Derajat sport through parameter tests so that it helps and can be a benchmark for determining the training program for KODRAT Kediri district. This study uses tests and measurements of 7 components of the physical condition test that are used to support physical abilities for combat athletes. In this study, the data analysis technique used to test the data in this study is descriptive percentage analysis. Where the results of the research data are calculated as a percentage of how many athletes are in the very good, good, sufficient, less and very poor categories. After analyzing the research data, it can be concluded that the overall physical condition of the fighting athletes at the Kediri Regency Puslatkab $47 \%$ is included in the sufficient category, and 53\% is included in the less category.
\end{abstract}


Keywords: Parameter test, athlete Tarung Derajat

\section{A. Pendahuluan}

Cabang olahraga Tarung derajat menjadi salah satu cabang olahraga yang menyumbangkan prestasi bagi Kabupaten Kediri, dan raihan prestasinya tidak kalah dengan cabang olahraga lainnya. Prestasi cabang olahraga Tarung Derajat di wilayah Jawa Timur tergolong membanggakan bagi Kabupaten Kediri meskipun masih belum maksimal dalam mempersembahkan medali disetiap eventnya. Pencapaian prestasi Tarung Derajat yang ada saat ini perlu ditingkatkan lagi agar bisa mencapai hasil yang maksimal. Banyak jalan untuk mendorong peningkatan prestasi cabang olahraga. Salah satunya adalah dengan mengevaluasi atau mengukur tingkat kondisi fisik masing-masing atlet. Dengan mengukur kondisi fisik atlet akan mendapatkan data yang bisa membantu pelatih menentukan program latihan yang tepat digunakan pada saat latihan. Selain itu dengan memperoleh data kondisi fisik atlet, dapat digunakan sebagai catatan maupun acuan untuk menbina atlet yang akan menjadi penerusnya. Komponen kondisi fisik yang dapat diukur untuk mengetahui kemampuan atlet. Kondisi fisik adalah satu prasyarat yang sangat diperlukan dalam usaha peningkatan prestasi seorang atlet, bahkan dapat dikatakan sebagai dasar landasan titik tolak suatu awalan olahraga prestasi. Tarung derajat adalah seni bela diri yang berasal dari Indonesia diciptakan oleh Achmad Dradjat. Beliau mengembangkan teknik bela diri melalui pengalamannya bertarung dijalanan pada tahun 1960an dibandung. Tes dan pengukuran merupakan istilah yang berbeda namun saling berhubungan. Tes adalah instrument atau alat yang digunakan untuk memperoleh informasi atau data, tes harus dirancang secara khusus. Pengukuran adalah pengumpulan data atau informasi yang dilakukan secara objektif. Melalui kegiatan pengukuran, segala program yang menyangkut perkembangan dalam bidang apa saja dapat dikontrol dan dievaluasi.

\section{B. Metode}

Pada penelitian ini menggunakan desain deskriptif kuantitatif survei. Menurut Maksum (2012:68) penelitian deskriptif adalah penelitian yang dilakukan untuk menggambarkan gejala, fenomena atau peristiwa tertentu. Pengumpulan data dilakukan untuk mendapatkan informasi terkait dengan fenomena, kondisi, atau variabel tertentu dan tidak dimaksudkan untuk melakukan pengujian hipotesis. Variabel dalam penelitian ini merupakan variabel tunggal yaitu kondisi fisik atlet Tarung Derajat Kabupaten Kediri, yang terdiri dari komponen kondisi fisik antara lain: Kelentukan menurut Iwan Setiawan (2005:67) adalah kemampuan seseorang untuk dapat melakukan gerak dengan ruang gerak seluas-luasnya dalam persendiannya. Kelentukan sebagai salah satu komponen kondisi fisik merupakan kemampuan menggerakkan bagian-bagian tubuh seluas mungkin tanpa terjadi cedera. Pada penelitian ini menggunakan sit and reach atau tes baring duduk. Menurut Sukadiyanto (2002:108) kecepatan adalah kemampuan seseorang untuk melakukan gerak atau serangkaian gerak secepat mungkin sebagai jawaban terhadap rangsang. Kecepatan adalah kemampuan bergerak menempuh jarak tertentu dengan waktu tercepat. Pada penelitian ini menggunakan tes lari 20 meter.

Kelincahan adalah kemampuan seseorang mengubah posisi diarea tertentu. Menurut Nugroho, T. P. (2005) kelincahan adalah kemampuan mengubah arah dengan cepat dan efektif, sambil bergerak atau berlari dengan cepat dam kecepatan penuh. Kelincahan adalah kemampuan mengubah arah dan posisi bagian tubuh secara cepat dan tepat. Untuk mengukur kelincahan menggunakan tes T-Test. Daya tahan atau endurance adalah kemampuan dari organisme untuk 
melawan kelelahan yang timbul dalam melakukan kegiatan jasmani dalam waktu yang lama, jika orang yang tahan lama melakukan suatu aktivitas Kardinan, I. A., \& Kusuma, F. R. (2004). Daya tahan adalah kemampuan sesorang dalam mempergunakan sistem jantung, pernafasan dan peredaran darahnya secara efektif dan efisien dalam menjalankan aktivitas secara terus menerus tanpa mengalami kelelahan yang berarti. Pengukuran daya tahan pada penelitian ini menggunakan tes MFT (Multistage Fitness Tes). Kekuatan atau strenght di kemukakan Subarjah, H. (2012) adalah kemampuan (kesanggupan) otot untuk dapat mempergunakan kekuatan melawan tahanan. Kekuatan adalah tenaga kontraksi otot yang dicapai dalam sekali usaha maksimal. Usaha maksimal dilakukan oleh otot atau sekelompok otot untuk mengatasi suatu tahanan. Pada penelitian ini ada 3 kelompok otot yang akan di tes yaitu: otot kaki menggunakan leg strength dengan alat leg dynamometer, otot lengan menggunakan tes push up 30 detik.

Pendapat yang dikemukakan oleh Broto, Dp (2015) power adalah kemampuan seseorang untuk mempergunakan kekuatan dan kecepatan maksimal yang dikerahkan dalam waktu yang sependek-pendeknya. Pengukuran daya ledak pada penelitian ini menggunakan tes Vertical Jump. Pada penelitian ini yang menjadi subjek penelitian adalah atlet PUSLATKAB Tarung Derajat kediri yang berjumlah 15 atlet. Rentang umur dari 13-20 tahun. Yang terdiri dari 4 perempuan dan 11 laki-laki. Lokasi pengambilan data penelitian akan dilakukan di Kampus 4 Universitas Nusantara PGRI Kediri. Waktu penelitian dilaksanakan pada bulan Desember 2021. Teknik pengumpulan data pada penelitian ini adalah menggunakan teknik pengumpulan data tes dan pengukuran. Atlet akan dikumpulkan pada gedung kampus 4 UN PGRI Kediri. Sebelum melaksanakan tes akan diberikan kesempatan untuk melakukan pemanasan disetiap pos-posnya selama 5-10 menit. Tes dilakukan bergantian antara anggota gerak tubuh bagian atas dan bawah, agar ada masa istirahat di kelompok otot yang baru saja melakukan gerakan ketika tes. Setiap pos telah disiapkan peralatannya, atlet secara bersama-sama dipandu oleh peneliti dan 2 orang anggota melewati pos demi pos sesuai dengan urutan di atas. Hasil yang didapat disetiap pos dicatat dalam lembar penilaian. Setelah didapatkan kategori pada setiap komponen kondisi fisik kemudian langkah berikutnya adalah mengambil kesimpulan dari penelitian yang telah dilakukan. Analisis data menggunakan teknik analisis deskriptif kuantitatif dengan presentase.

\section{Hasil dan Pembahasan}

Penelitian ini menggunakan tes dan pengukuran terhadap 7 komponen tes kondisi fisik yang digunakan untuk menunjang kemampuan fisik bagi atlet tarung derajat. Penelitian ini teknik analisis data yang digunakan untuk menguji data dalam penelitian ini adalah analisis deskriptif persentase. Dimana hasil dari data penelitian dihitung dalam jumlah persen berapa atlet yang dalam katagori baik sekali, baik, cukup, kurang dan kurang sekali. Penelitian ini bertujuan untuk mengetahui kondisi fisik atlet tarung derajat pada Puslatkab Kediri. Data yang diambil dalam penelitian ini adalah meliputi Kelentukan, kecepatan, kelincahan, VO2Max, kekuatan otot tungkai, kekuatan otot lengan, power otot tungkai.

Tabel 1. Data hasil parameter tes atlet putra kabupaten kediri

\begin{tabular}{|c|c|c|c|c|c|c|c|c|}
\hline No & Nama & Kelentukan & $\begin{array}{c}\text { Kekuatan } \\
\text { Otot } \\
\text { Kaki }\end{array}$ & $\begin{array}{c}\text { Kekuatan Otot } \\
\text { Tangan }\end{array}$ & Kelincahan & Kecepatan & $\begin{array}{c}\text { Tinggi } \\
\text { Lompatan }\end{array}$ & Vo2max \\
\hline 1 & Ahna & 1 & 6 & 29.0 & 15.25 & 5.13 & 2 & 2 \\
\hline
\end{tabular}




\begin{tabular}{lcllllll}
\hline 2 & istina Dwi & 1 & 6 & 29.0 & 13.80 & 4.72 & 2 \\
3 & Riska & 1 & 8 & 28.0 & 14.55 & 4.47 & 3 \\
4 & Aurelia & 1 & 7 & 28.0 & 13.72 & 4.06 & 3 \\
5 & & & & & & \\
\hline
\end{tabular}

Tabel 2. Data hasil parameter tes atlet putri kabupaten kediri

\begin{tabular}{|c|c|c|c|c|c|c|c|c|}
\hline No & Nama & Kelentukan & $\begin{array}{c}\text { Kekuatan Otot } \\
\text { Kaki }\end{array}$ & $\begin{array}{c}\text { Kekuatan } \\
\text { Otot Tangan }\end{array}$ & Kelincahan & Kecepatan & Tinggi Lompatan & Vo2max \\
\hline 1 & Devas Linsiana & 3 & 135. & 39.0 & 11.24 & 3.89 & 5 & 4 \\
\hline 2 & Vairus Abadi & 1 & 110. & 32.0 & 11.38 & 3.58 & 4 & 4 \\
\hline 3 & Ahmad & 2 & 145. & 44.0 & 10.02 & 3.81 & 5 & 4 \\
\hline 4 & Abimanyu Aryo & 1 & 40. & 20.0 & 13.11 & 4.11 & 2 & 3 \\
\hline 5 & Sultan & 1 & 120. & 34.0 & 12.10 & 3.61 & 5 & 4 \\
\hline 6 & Heru Johandi & 2 & 110. & 41.0 & 10.77 & 3.45 & 4 & 4 \\
\hline 7 & Sigit Cahyono & 2 & 110. & 35.0 & 11.42 & 3.39 & 6 & 4 \\
\hline 8 & Andika & 1 & 115. & 34.0 & 10.98 & 3.58 & 5 & 5 \\
\hline 9 & M Safik Amrul & 2 & 112. & 34.0 & 11.97 & 3.66 & 5 & 4 \\
\hline 10 & Abdul Malik & 2 & 115. & 32.0 & 13.40 & 3.17 & 4 & 4 \\
\hline 11 & M Dai & 2 & 110. & 42.0 & 12.01 & 3.20 & 5 & 4 \\
\hline
\end{tabular}

Tabel 3. Rekapituasi data hasil tes parameter atlet putra

\begin{tabular}{|c|c|c|c|c|c|c|c|c|c|c|c|c|c|c|c|c|c|c|c|c|c|c|c|c|}
\hline \multirow{3}{*}{ No } & \multirow{3}{*}{ Nama } & \multirow{2}{*}{\multicolumn{3}{|c|}{$\begin{array}{l}\text { Kelentukan } \\
\text { Sit and Reach }\end{array}$}} & \multirow{2}{*}{\multicolumn{3}{|c|}{$\begin{array}{c}\begin{array}{c}\text { Kekuatan otot } \\
\text { kaki }\end{array} \\
\text { Leg } \\
\text { Dynamometer }\end{array}$}} & \multicolumn{3}{|c|}{$\begin{array}{c}\text { Kekuatan } \\
\text { Otot } \\
\text { Tangan } \\
\end{array}$} & \multicolumn{3}{|c|}{ Kelincahan } & \multicolumn{3}{|c|}{ Kecepatan } & \multicolumn{3}{|c|}{$\begin{array}{c}\text { Tingg } \\
\text { Lompatan }\end{array}$} & \multicolumn{3}{|c|}{ VO2 Max } & \multirow{3}{*}{ 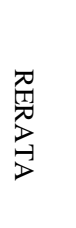 } & \multirow{3}{*}{ 蒏 } \\
\hline & & & & & & & & \multicolumn{3}{|c|}{ Push Up } & \multicolumn{3}{|c|}{$\mathrm{T}-$ Test } & \multicolumn{3}{|c|}{ Lari $20 \mathrm{M}$} & \multicolumn{3}{|c|}{$\begin{array}{l}\text { Vertical } \\
\text { Jump }\end{array}$} & \multicolumn{3}{|c|}{ Bleep Test } & & \\
\hline & & $\mathrm{H}$ & $\mathrm{N}$ & K & $\mathrm{H}$ & $\mathrm{N}$ & K & $\mathrm{H}$ & $\mathrm{N}$ & $\mathrm{K}$ & $\mathrm{H}$ & $\mathrm{N}$ & K & $\mathrm{H}$ & $\mathrm{N}$ & K & $\mathrm{H}$ & $\mathrm{N}$ & K & $\mathrm{H}$ & $\mathrm{N}$ & $\bar{K}$ & & \\
\hline 1 & Devas Linsiana $\mathrm{S}$ & 34.0 & 5 & BS & 135.00 & 3 & $\mathrm{C}$ & 39.0 & 4 & B & 11.2 & 3 & $\mathrm{C}$ & 3.89 & 1 & KS & 51 & 2 & K & 45.8 & 3 & $\mathrm{C}$ & 3 & $\mathrm{c}$ \\
\hline 2 & Vairus Abadi & 19.5 & 5 & BS & 110.00 & 2 & $\mathrm{~K}$ & 32.0 & 3 & $\mathrm{C}$ & 11.4 & 3 & $\mathrm{C}$ & 3.58 & 2 & $\mathrm{~K}$ & 47 & 2 & $\mathrm{~K}$ & 47.4 & 3 & $\mathrm{C}$ & 3 & $\mathrm{C}$ \\
\hline 3 & Ahmad Chabibudaiman & 25.0 & 5 & $\mathrm{BS}$ & 145.00 & 3 & $\mathrm{C}$ & 44.0 & 5 & BS & 10.0 & 4 & $\mathrm{~B}$ & 3.81 & 1 & KS & 57 & 3 & $\mathrm{C}$ & 46.8 & 3 & $\mathrm{C}$ & 3 & $\mathrm{C}$ \\
\hline 4 & Abimanyu Aryo & 19.5 & 5 & BS & 40.00 & 1 & KS & 20.0 & 2 & $\mathrm{~K}$ & 13.1 & 1 & KS & 4.11 & 1 & KS & 26 & 1 & KS & 37.8 & 1 & $\mathrm{KS}$ & 2 & K \\
\hline 5 & Sultan Fernando & 14.0 & 2 & $\mathrm{~K}$ & 120.00 & 2 & $\mathrm{~K}$ & 34.0 & 3 & $\mathrm{C}$ & 12.1 & 2 & $\mathrm{~K}$ & 3.61 & 1 & KS & 54 & 3 & $\mathrm{C}$ & 41.8 & 2 & $\mathrm{~K}$ & 2 & K \\
\hline 6 & Heru Johandi & 25.5 & 5 & BS & 110.00 & 2 & K & 41.0 & 4 & B & 10.8 & 3 & $\mathrm{C}$ & 3.45 & 2 & $\mathrm{~K}$ & 48 & 2 & $\mathrm{~K}$ & 47.4 & 3 & $\mathrm{C}$ & 3 & C \\
\hline 7 & Sigit Cahyono & 28.0 & 5 & BS & 110.00 & 2 & $\mathrm{~K}$ & 35.0 & 4 & B & 11.4 & 3 & $\mathrm{C}$ & 3.39 & 2 & K & 65 & 4 & B & 46.8 & 3 & $\mathrm{C}$ & 3 & $\mathrm{C}$ \\
\hline 8 & Andika Lugistiro & 15.5 & 3 & $\mathrm{C}$ & 115.00 & 2 & K & 34.0 & 3 & $\mathrm{C}$ & 11.0 & 3 & $\mathrm{C}$ & 3.58 & 2 & K & 53 & 3 & $\mathrm{C}$ & 51.9 & 3 & $\mathrm{C}$ & 3 & C \\
\hline 9 & M safik Amrul & 27.5 & 5 & BS & 112.00 & 2 & K & 34.0 & 3 & $\mathrm{C}$ & 12.0 & 2 & $\mathrm{~K}$ & 3.66 & 1 & KS & 58 & 3 & $\mathrm{C}$ & 43.3 & 2 & $\mathrm{~K}$ & 3 & K \\
\hline 10 & Abdul Malik & 23.5 & 5 & BS & 115.00 & 2 & $\mathrm{~K}$ & 32.0 & 3 & $\mathrm{C}$ & 13.4 & 1 & $\mathrm{KS}$ & 3.17 & 3 & $\mathrm{C}$ & 40 & 1 & KS & 46.0 & 3 & $\mathrm{C}$ & 3 & K \\
\hline 11 & M Dai Kurniawan & 22.0 & 5 & BS & 110.00 & 2 & $\mathrm{~K}$ & 42.0 & 4 & B & 12.0 & 2 & $\mathrm{~K}$ & 3.20 & 3 & $\mathrm{C}$ & 53 & 3 & $\mathrm{C}$ & 48.0 & 3 & $\mathrm{C}$ & 3 & C \\
\hline 12 & 0 & 0.0 & 0 & $\mathrm{TI}$ & 0.00 & 0 & TI & 0.0 & 0 & TI & 0.0 & 0 & TI & 0.00 & 0 & TI & 0 & 0 & TI & 0.0 & 0 & TI & 0 & $\mathrm{~T}$ \\
\hline 13 & 0 & 0.0 & 0 & TI & 0.00 & 0 & TI & 0.0 & 0 & TI & 0.0 & 0 & TI & 0.00 & 0 & TI & 0 & 0 & TI & 0.0 & 0 & TI & 0 & $\mathrm{~T}$ \\
\hline 15 & 0 & 0.0 & 0 & TI & 0.00 & 0 & TI & 0.0 & 0 & $\mathrm{TI}$ & 0.0 & 0 & $\mathrm{TI}$ & 0.00 & 0 & TI & 0 & 0 & TI & 0.0 & 0 & TI & 0 & $\mathrm{~T}$ \\
\hline
\end{tabular}

Tabel 4. Rekapituasi data hasil tes parameter atlet putri

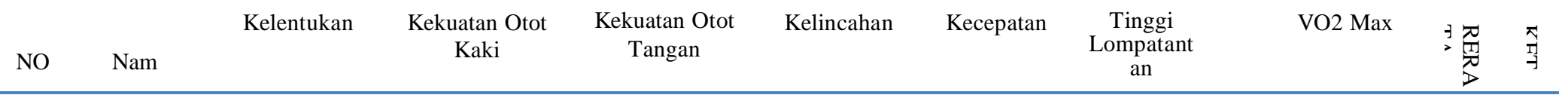




\begin{tabular}{|c|c|c|c|c|c|c|c|c|c|c|c|c|c|c|c|c|c|c|c|c|c|c|c|}
\hline & \multirow[t]{2}{*}{$\mathrm{a}$} & \multicolumn{3}{|c|}{$\begin{array}{l}\text { Sit And } \\
\text { Reach }\end{array}$} & \multicolumn{3}{|c|}{$\begin{array}{c}\text { Leg } \\
\text { Dynamometer }\end{array}$} & \multicolumn{4}{|c|}{ Push Up } & \multicolumn{2}{|c|}{ T - Test } & \multicolumn{3}{|c|}{ Lari $20 \mathrm{M}$} & \multicolumn{3}{|c|}{$\begin{array}{l}\text { Vertical } \\
\text { Jump }\end{array}$} & \multicolumn{3}{|c|}{ Bleep Test } & \\
\hline & & $\mathrm{H}$ & $N$ & $\mathrm{~K}$ & $\mathrm{H}$ & $\mathrm{N}$ & $\mathrm{K}$ & $\mathrm{H}$ & $\mathrm{N}$ & $\mathrm{K}$ & $\mathrm{H}$ & $\mathrm{N}$ & $\mathrm{K}$ & $\mathrm{H}$ & $\mathrm{N}$ & $\mathrm{K}$ & $\mathrm{H}$ & $\mathrm{N}$ & $\mathrm{K}$ & $\mathrm{H}$ & $\mathrm{N}$ & $\mathrm{K}$ & \\
\hline 1 & Ahna & 19 & 4 & B & 6 & 1 & KS & 2 & 4 & B & 1 & 1 & K & 5 & 1 & K & 2 & 2 & $\mathrm{~K}$ & 2 & 1 & $\mathrm{KS}$ & 2 \\
\hline 2 & Istina Dwi & 18 & 3 & $\mathrm{C}$ & 6 & 1 & $\mathrm{KS}$ & 2 & 4 & B & 1 & 1 & $\mathrm{~K}$ & 4 & 1 & $\mathrm{~K}$ & 2 & 2 & K & 2 & 1 & KS & 2 \\
\hline 3 & Riska & 16 & 2 & $\mathrm{~K}$ & 8 & 1 & $\mathrm{KS}$ & 2 & 4 & B & 1 & 1 & $\mathrm{~K}$ & 4 & 1 & $\mathrm{~K}$ & 3 & 3 & $\mathrm{C}$ & 2 & 2 & $\mathrm{~K}$ & 2 \\
\hline 4 & Aurelia & 17 & 3 & $\mathrm{C}$ & 7 & 1 & KS & 2 & 4 & B & 1 & 1 & $\mathrm{~K}$ & 4 & 1 & $\mathrm{~K}$ & 3 & 4 & B & 3 & 2 & K & 2 \\
\hline 5 & 0 & 0. & 0 & $\mathrm{~T}$ & 0 & 0 & $\mathrm{TI}$ & 0 & 0 & TI & 0 & 0 & $\mathrm{~T}$ & 0 & 0 & $\mathrm{~T}$ & 0 & 0 & $\mathrm{~T}$ & 0 & 0 & $\mathrm{TI}$ & 0 \\
\hline 6 & 0 & 0. & 0 & $\mathrm{~T}$ & 0 & 0 & TI & 0 & 0 & TI & 0 & 0 & $\mathrm{~T}$ & 0 & 0 & $\mathrm{~T}$ & 0 & 0 & $\mathrm{~T}$ & 0 & 0 & $\mathrm{TI}$ & 0 \\
\hline 7 & 0 & 0. & 0 & $\mathrm{~T}$ & 0 & 0 & TI & 0 & 0 & TI & 0 & 0 & $\mathrm{~T}$ & 0 & 0 & $\mathrm{~T}$ & 0 & 0 & $\mathrm{~T}$ & 0 & 0 & TI & 0 \\
\hline 8 & 0 & 0. & 0 & $\mathrm{~T}$ & 0 & 0 & TI & 0 & 0 & TI & 0 & 0 & $\mathrm{~T}$ & 0 & 0 & $\mathrm{~T}$ & 0 & 0 & $\mathrm{~T}$ & 0 & 0 & TI & 0 \\
\hline
\end{tabular}

Keterangan:

$\begin{array}{ll}\text { BS } & \text { : Baik Sekali } \\ \text { B } & \text { : Baik } \\ \text { C } & \text { : Cukup } \\ \text { K } & \text { : Kurang } \\ \text { KS } & \text { : Kurang Sekali } \\ \text { TI } & \text { : Tidak Ikut }\end{array}$

Dari hasil penelitian di atas, masih banyak atlet yang memiliki kondisi fisik yang masuk dalam kategori kurang dan cukup. Salah satu faktor yang mempengaruhi kondisi fisik seorang atlet tarung derajat yaitu faktor latihan. Latihan adalah suatu proses berlatih secara sistematis yang dilakukan berulang-ulang dan kian hari beban latihannya kian bertambah. Latihan tidak hanya kuantitas atau jumlah berlatih saja yang diutamakan, akan tetapi kualitas atau mutu latihan harus benar-benar diperhatikan baik oleh pelatih maupun seorang atlet. Latihan yang tidak sesuai dengan kebutuhan atlet akan mengakibatkan ketidakefektifan dalam mencapai kondisi fisik yang diharapkan. Untuk mencapai tingkat kondisi fisik sesuai dengan yang diharapkan maka diperlukan latihan secara kontinyu. Porsi dalam berlatih olahraga bukan hanya masalah kuantitas (berapa banyak kita berlatih) akan tetapi juga masalah kualitas dan kontinuitas. Kualitas menggambarkan efektifitas dari latihan itu sendiri sedangkan kontinuitas mendeskripsikan keseriusan dan kemampuan untuk tetap menjaga kebugaran tubuh seseorang. Selain penambahan beban latihan frekuensi latihan juga harus diperhatikan untuk meningkatkan prestasi atlet.

Pelaksanaan program latihan hendaknya memperhatikan prinsip-prinsip latihan yang ada. Dalam olahraga, latihan harus mempunyai tujuan yang pasti, mempunyai prinsip latihan serta berpengaruh pada cabang olahraga yang diikutinya, bahwa ada pengaruhnya dalam kehidupan sehari-hari. Tujuan latihan adalah peningkatan prestasi yang maksimal, peningkatan kesehatan dan peningkatan kondisi fisik. Kenyataan yang terjadi dalam pelaksanaan latihan fisik, jadwal latihan yang tidak teratur dan juga para atlet yang tidak serius dalam mengikuti latihan fisik. Hal tersebut menjadikan latihan fisik yang ada menjadi tidak maksimal. Berdampak pada kondisi fisik para atlet menjadi kurang baik. Untuk itu diharapkan adanya perubahan dalam jadwal serta program latihan fisik yang ada, serta penambahan porsi latihan fisik menjadi lebih banyak dari porsi sekarang ini. Diharapkan dengan adanya perubahan serta penambahan porsi latihan fisik akan meningkatkan kondisi fisik para atlet, sehingga para atlet mempunyai kondisi fisik yang lebih baik. 


\section{Kesimpulan}

Setelah dilakukan analisis data penelitian mengenai kondisi fisik 15 atlet tarung derajat pada Puslatkab Kediri maka dapat diambil beberapa kesimpulan bahwa kondisi fisik secara keseluruhan atlet tarung derajat pada Puslatkab Kediri 47\% termasuk dalam cukup, 53\% termasuk dalam kurang. Kondisi fisik pada dasarnya dapat dimiliki oleh atlet secara maksimal melalui latihan-latihan yang diprogram dan direncanakan dengan baik serta didukung dengan kesungguhan oleh atlet itu sendiri. Dalam pelaksanaan latihan para atlet hendaknya tidak meninggalkan prinsip-prinsip latihan diantaranya penambahan beban, pengulangan, ada tingkatan dan memiliki target. Apabila prinsip-prinsip latihan itu selalu dilakukan, dan atlet itu melakukan latihan dengan sungguh-sungguh dengan program latihan yang baik, maka seorang atlet bisa memiliki kondisi fisik yang bagus. Untuk pelatih, disarankan untuk menambah program latihan fisik dan membuat program latihan yang teratur dan terencana, supaya para atlet tarung derajat pada Puslatkot Kediri memiliki kondisi fisik yang bagus. Dengan adanya program latihan fisik yang teratur dan terencana, diharapkan para atlet tarung derajat pada Puslatkot Kediri merasa lebih bersemangat untuk berlatih, karena latihan yang diberikan terasa tidak monoton.

\section{Daftar Pustaka}

Bompa, T. O., \& Buzzichelli, C. (2019). Periodization-: theory and methodology of training. Human kinetics.

Broto, Dp (2015). Pengaruh Latihan Plyometrics Terhadap Power Otot Tungkai Atlet Remaja Bola Voli. Gerak: Jurnal Riset Pendidikan Jasmani , 6 (2), 174-185.

Erfan, M. (2020). Pengaruh Latihan Plyometric (Pullover Toss) Terhadap Hasil (Throw In) Dalam Permainan Sepak Bola. Jurnal Porkes, 3(2), 110-118.

Effendi, H. (2016). Peranan psikologi olahraga dalam meningkatkan prestasi atlet. NUSANTARA: Jurnal Ilmu Pengetahuan Sosial, 1(1).

Fagesta, R., Syamsuramel, S., \& Iyakrus, I. (2018). Pengaruh Latihan Agility Ladder Drill Untuk Meningkatkan Kelincahan Pada Kegiatan Ekstrakurikuler Sepak Bola Smp Negeri 2 Belitang (Doctoral dissertation, Sriwijaya University).

Harsono. 2001. Latihan Kondisi Fisik. Bandung: November.

Ihsan, N. (2017, March). Development of speed measurement system for pencak silat kick based on sensor technology. In IOP Conference Series: Materials Science and Engineering (Vol. 180, No. 1, p. 012171). IOP Publishing.

Issurin, V. B. (2010). New horizons for the methodology and physiology of training periodization. Sports medicine, 40(3), 189-206.

Iwan Setiawan, dkk. 2005. Manusia Dan Olahraga. Bandung: ITB

Johnson, Barry L., J. K. Nelson. 2000. Practical Measurements for Evaluation in Physical Education. Champaign, IL : Human Kinetics

Kemenpora. 2005. Panduan Penetapan Parameter Tes Pada Pusat Pendidikan Dan Pelatihan Pelajar Dan Sekolah Khusus Olahragawan. Yogjakarta : Kemenpora

Kurniawan. 2011. Buku Pintar Olahraga. Jakarta: Laskar Aksara

Kardinan, I. A., \& Kusuma, F. R. (2004). Meniran penambah daya tahan tubuh alami. Agro Media. 
Creating Productive and Upcoming Sport Education Profesional Hmzanwadi University Vol.4, No.2, Desember 2021, Hal. 158-164

e-ISSN 2614-8781

Lestari, I. D., Rizky, M. Y., \& Pratama, B. A. (2021). Analisis Kondisi Fisik Cabor Combat Unggulan Kota Kediri Menuju Porprov Vii Tahun 2022 (Doctoral dissertation, Universitas Nusantara PGRI Kediri).

Maksum, Ali. 2012. Metodologi Penelitian Pendidikan Jasmani. Surabaya : Unesa

Morrow, James R, Jr., A. W.Jackson, J. G. Disch \& D. L. Mood. 2000. Measurement and Evaluation in Human Performance. Champaign, IL: Human Kinetics

Muhyi \& Albertus. 2015. Tes dan Pengukuran Dalam Olahraga. Yogjakarta : Andi Offset

Mansur, M., Kurniawan, F., Irianto, S., Herwin, H., \& Nurfadhila, R. (2020). Analisis dan evaluasi kondisi fisik (kelincahan) atlet cabang olahraga unggulan Kabupaten Kebumen Provinsi Jawa Tengah. Jorpres (Jurnal Olahraga Prestasi), 16(2), 72-77.

Nugroho, T. P. (2005). "Hubungan Antara Kecepatan dan Kelincahan terhadap Ketrampilan Menggiring Bola dalam Sepak Bola pada Siswa Lembaga Pendidikan Sepakbola Atlas Binatama Semarang" (Doctoral dissertation, Universitas Negeri Semarang).

Perdana. 2009. Profil Kondisi Fisik Atlet PAB DIY Tahun 2009. Skripsi. Yogyakarta: FIK UNY

Prayoga, H. D., Fitrianto, A. T., \& Habibie, M. (2020). Perbandingan Kemampuan Fisik Dasar Petinju Nasional Dengan Petinju Daerah. Jurnal Porkes, 3(2), 149-158.

Penggalih, M. H. S. T., \& Huriyati, E. (2007). Gaya hidup, status gizi dan stamina atlet Pada sebuah klub sepakbola. Berita Kedokteran Masyarakat, 23(4), 192-199.

Rosiana, A. M. (2013). Hubungan antara kondisi fisik rumah dengan kejadian tuberkulosis paru di wilayah kerja Puskesmas Kedungmundu Kota Semarang. Unnes Journal of Public Health, 2(1).

Septiana. 2015. Profil Kondisi Fisik Atlet Pelatihan Daerah Baseball Daerah Istimewa Yogyakarta. Skripsi. Yogyakarta: FIK UNY

Syahda, I. A., Damayanti, I., \& Imanudin, I. (2016). Hubungan Kapasitas Vital Paru-Paru Dengan Daya Tahan Cardiorespiratory Pada Cabang Olahraga Sepak Bola. JTIKOR (Jurnal Terapan Ilmu Keolahragaan), 1(1), 24-28.

Subarjah, H. (2012). Latihan kondisi fisik. Diperoleh tanggal, 12.

Sukadiyanto. 2002. Teori dan Metodologi Melatih Fisik Petenis. Yogyakarta: UNY

Yusni, Y., \& Amiruddin, A. (2020). Efek suplementasi kalsium terhadap kebugaran dan profil kesehatan pada atlet tarung derajat. Jurnal Keolahragaan, 8(1), 42-51. 